\title{
Exposure to asbestos and the risk of gastrointestinal cancer: a reassessment
}

\author{
D A EDELMAN \\ From Medical Research Consultants, Inc, Chapel Hill, North Carolina, USA
}

\begin{abstract}
In 1964 it was first reported that asbestos workers had a higher risk of gastrointestinal cancer. This notion has persisted despite several studies that have found no increased risk. The risks of gastrointestinal cancer to workers exposed to asbestos were reassessed, based on the results of published studies on 32 independent cohorts of asbestos workers. Not all studies provided risk estimates (SMRs) for all gastrointestinal sites (ICD codes 150-159). No consistent evidence was found to indicate that exposure to asbestos increases the risk of gastrointestinal cancer. Generally, the higher SMRs came from studies conducted in the United States or Canada and might reflect factors not related to exposure to asbestos. In studies in which asbestos exposed and non-asbestos exposed workers were evaluated the SMRs were not consistently higher for the group exposed to asbestos. There was no apparent dose response relation between accumulated asbestos dose and the risk of gastrointestinal cancer. It is concluded that there is no dose response relation between exposure to asbestos and risk of gastrointestinal cancer, and asbestos workers are not at an increased risk of gastrointestinal cancer.
\end{abstract}

In 1964 Selikoff and coworkers reported on the mortality experience of 632 asbestos insulation workers in the New York metropolitan area.' The study showed that these workers had an apparent excess of gastrointestinal cancers; there were 12 deaths from gastric cancer compared with $4 \cdot 3$ expected (standardised mortality ratio $(\mathrm{SMR})=2.79$ ) and 17 deaths from cancer of the colon or rectum compared with $5 \cdot 2$ expected (SMR = 3.27). Both SMRs were significantly greater than $1(\mathrm{p}<0.05)$, indicating an increased risk compared with all United States white men. In the 24 years since the publication of this paper the notion of an increased risk of gastrointestinal cancer to asbestos workers has persisted even though several other papers have failed to substantiate it.

In 1978 Miller reviewed reports relating to exposure to asbestos and the risk of gastrointestinal cancer and concluded that they were causally related. ${ }^{2}$ Another review was published in 1985 by Morgan et al who found some raised risks of cancer to some parts of the gastrointestinal tract but believed that these rises were not related to exposure to asbestos. ${ }^{3}$ The present paper provides a more detailed review of the risks of

Accepled 12 January 1987 gastrointestinal cancer to asbestos workers and is based on data from published studies. Studies that evaluated risks of gastrointestinal cancer from "bystander" exposure including exposures from asbestos contaminated drinking water were not included.

\section{Study methods}

Thirty two cohorts of asbestos exposed workers were identified that provided data on their risks of gastrointestinal cancer $^{+35}$; table 1 summarises the types of

Table 1 Occupational exposures to asbestos of cohorts evaluated

\begin{tabular}{ll}
\hline Industry occupational exposure & No of cohorts \\
\hline Ashestos cement & 4 \\
Insulation work & 1 \\
Manufacturing: & 2 \\
$\quad$ Gas masks & 9 \\
Papcr. millboard. friction products. ctc & 2 \\
Textiles & 5 \\
Mining and milling & 1 \\
Nitric acid production plant & 1 \\
Railroad & 3 \\
Shipyard dockyard & \\
Workers reported to registries. pneumoconiosis & 4 \\
panels. or applying for workman's compensation & 4 \\
\hline
\end{tabular}


Table 2 Standard mortality ratios (SMRs) for cancer of various gastrointestinal sites

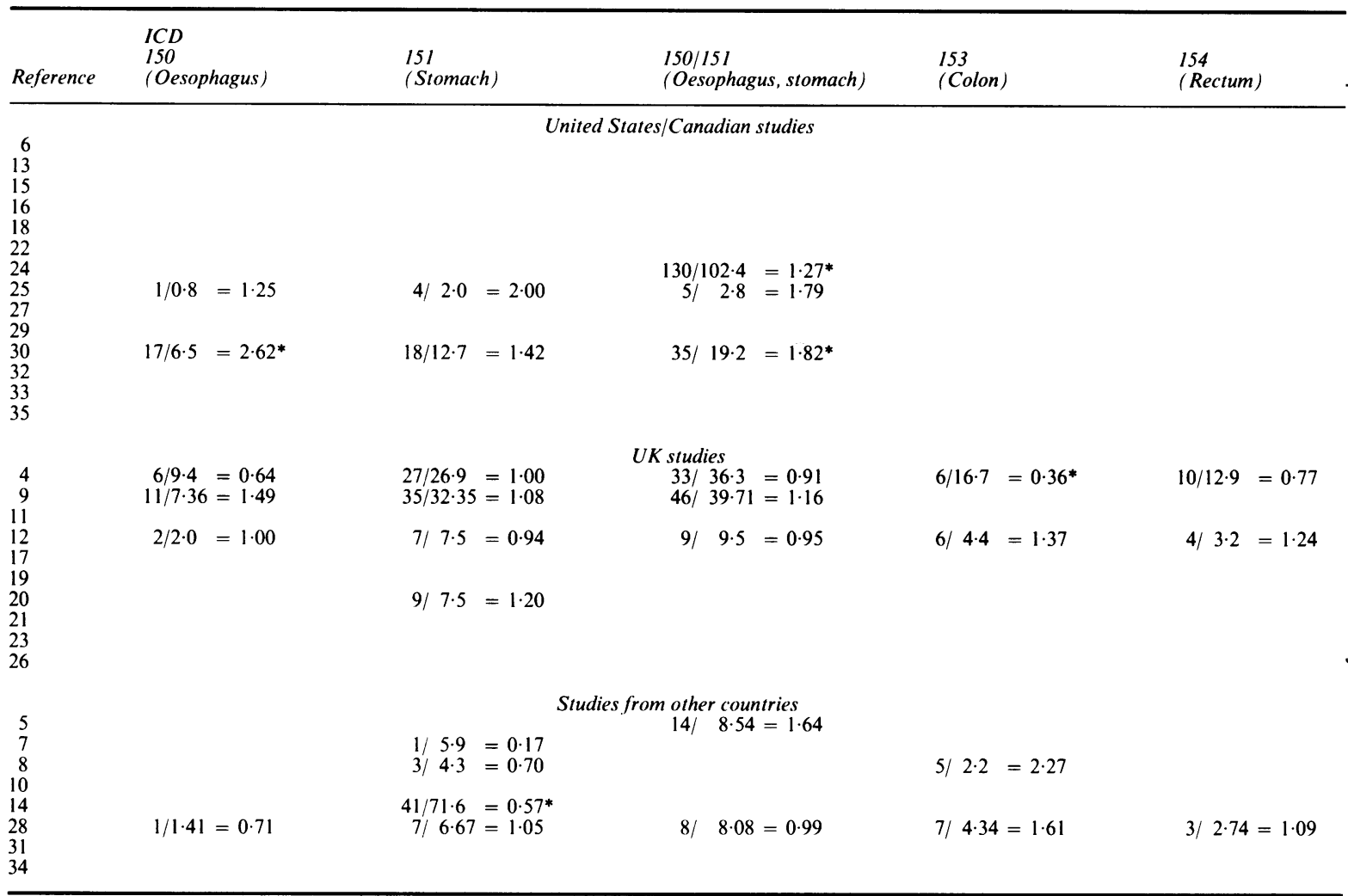

GI. Gastrointestinal.

${ }^{*} \mathrm{p}<0.05 ;{ }^{1} 150,151,153-154,{ }^{2} 152-154 ;{ }^{3} 151-154 ;{ }^{4}$ intestinal; ${ }^{5} 151-159 ;{ }^{6} 150-158$; 'digestive, probably $150-157$.

occupational exposure. Data on some of the cohorts have been published numerous times giving the illusion that there is considerably more evidence on the risks of gastrointestinal and other cancers to asbestos workers than actually exists. For each cohort the most up to date data have been used. Studies were included in the review if they provided data on the risks of cancer to any gastrointestinal site (International Classification of Diseases (ICD) codes 150-159). Studies that gave PMRs (proportional mortality ratios) or odds ratios were not included. If causes of death according to death certificate information and the best evidence of death based on medical and other evidence were given only the death certificate data were used.

The statistical significance of the SMRs was assessed assuming the observed number of deaths followed a Poisson distribution. Statistical tests of significance (two sided) were performed using the procedure described by Bailar and Ederer. ${ }^{36}$

The risks of gastrointestinal cancer (ICD codes 150)159) to asbestos workers were evaluated by considering the following:
(1) The SMRs for gastrointestinal cancers; (2) comparison of SMRs for gastrointestinal cancers for asbestos exposed and non-exposed workers; and (3) evaluation of the dose-response relation between the risk of gastrointestinal cancer and some measure of asbestos dose.

\section{SMRS FOR GASTROINTESTINAL CANCERS}

Table 2 shows the SMRs for cancers of various gastrointestinal sites for each of the 32 cohorts. The table separates the studies into those conducted in the United States, the United Kingdom, and other countries. Not all studies gave SMRs for all gastrointestinal sites. Some studies identified the cancers only as "gastrointestinal" (GI) without further indication as to which ICD codes were included.

Table 2 shows that, except for one study only in the United States/Canadian studies were any of the SMRs significantly $(p<0.05)$ greater than 1 . For ICD codes for which there were data from the United States/ Canada and other countries, the largest SMRs (regardless of whether or not they differed significantly 
Table 2 continued

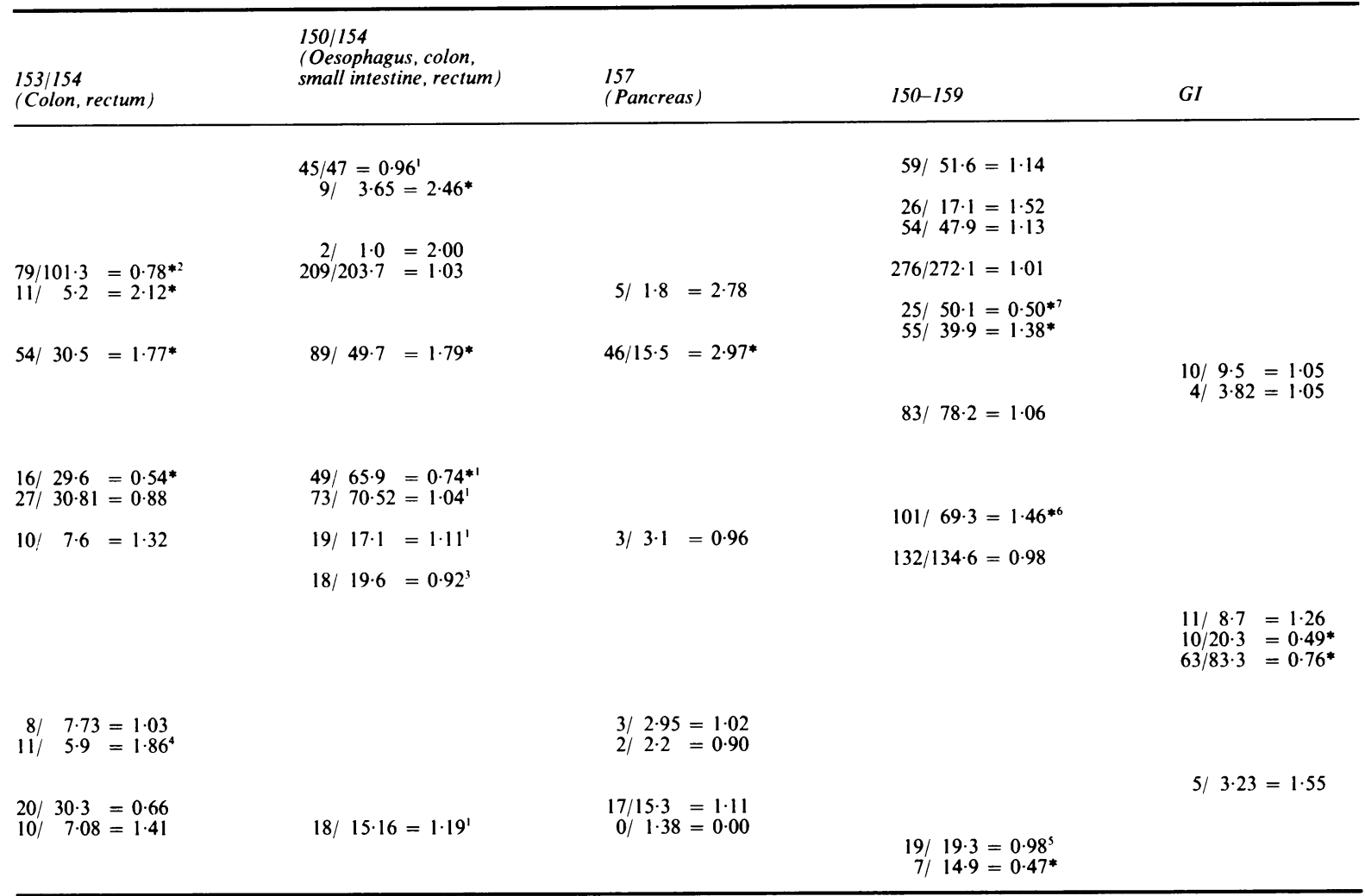

from 1) occurred in the United States/Canadian studies and the smallest occurred in studies conducted in other countries. This was true for all ICD codes except for the GI category. Since in most studies the expected number of deaths was calculated from national death rates, it might be hypothesised that in countries other than the United States and Canada the workers exposed to asbestos and national populations are more homogeneous and less subject to factors that might confound the relation between asbestos exposure and the risk of gastrointestinal cancer.

The data in table 3 summarises the SMRs given in table 2 . Ten were significantly greater than 1 $(\mathrm{p}<0.05)$ and nine were significantly less than 1 $(\mathrm{p}<0.05)$.

SMRS FOR ASBESTOS FXPOSED AND NONASBFSTOS FXPOSED WORKFRS

Six studies provided gastrointestinal cancer SMRs for non-asbestos exposed workers (table 4). No consistent pattern in the relative size of the pairs of SMRs is seen for the asbestos exposed and non-asbestos exposed workers. Six of the 12 SMRs shown in the table were lower for the asbestos exposed workers. The data presented in table 4 do not indicate any increased risk of gastrointestinal cancer for asbestos exposed compared with non-asbestos exposed workers.

\section{DOSE RESPONSE RELATION BETWEEN} EXPOSURE TO ASBESTOS AND

GASTROINTESTINAL CANCER

Dose response data were given in nine studies. The relation between the risk of death from gastrointestinal cancer, lung cancer, and in some cases other diseases, and the accumulated dose of asbestos is shown in the figure $(\mathrm{a}-\mathrm{g})$. No attempt was made to convert accumulated asbestos dose to common units. Deaths from lung cancer are also shown since many investigators have reported a dose response relation between the risk of lung cancer and asbestos dose. ${ }^{37}$ None of the studies listed in the figure computed dose response relation for lung cancer for workers with different lifetime smoking habits. Failure to do this could obscure a dose response relation, especially if the 
Table 3 Summary of SMRs given in table 2

\begin{tabular}{|c|c|c|c|c|c|}
\hline$I C D$ & Studies & Median $S M R$ & Range of SMRs & $\begin{array}{l}S M R s<1 \\
(p<0.05)\end{array}$ & $\begin{array}{l}S M R s>1 \\
(p<0.05)\end{array}$ \\
\hline $\begin{array}{l}150 \\
151 \\
150-151 \\
153 \\
154 \\
153-154 \\
150-154 \\
157 \\
150-159 \\
\text { Gastrointestinal }\end{array}$ & $\begin{array}{r}6 \\
9 \\
8 \\
4 \\
3 \\
10 \\
10 \\
7 \\
11 \\
6\end{array}$ & $\begin{array}{l}1.13 \\
1.00 \\
1.22 \\
1.49 \\
1.09 \\
1.18 \\
1.08 \\
0.99 \\
1.06 \\
1.05\end{array}$ & $\begin{array}{l}0.64-2.62 \\
0.17-2.04 \\
0.91-1.82 \\
0.36-2.27 \\
0.77-1.24 \\
0.74-2.46 \\
0.74-2.46 \\
0.00-2.97 \\
0.47-1.52 \\
0.49-1.55\end{array}$ & $\begin{array}{l}0 \\
1 \\
0 \\
1 \\
0 \\
2 \\
1 \\
0 \\
2 \\
2\end{array}$ & $\begin{array}{l}1 \\
0 \\
2 \\
0 \\
0 \\
2 \\
2 \\
1 \\
2 \\
0\end{array}$ \\
\hline
\end{tabular}

smoking habits of the asbestos workers differ from those of the populations with whom the asbestos workers are compared.

The figure shows no consistent dose response relation for gastrointestinal cancers. Although the data from some studies suggest dose response relations, they are most probably an artifact of the way in which accumulated dose was measured. For example, McDonald et al in their study of miners and millers show that the SMR for colon and rectal cancer increases with accumulated asbestos dose. ${ }^{24}$ They also show that the same relation exists for deaths from respiratory tuberculosis and cerebrovascular disease. In another study of miners and millers death rates from lung cancer, gastrointestinal cancer (ICD 151159), tuberculosis of the lung, and cardiovascular disease increased with increasing accumulated dose of asbestos. ${ }^{31}$ Since diseases such as cardiovascular disease and respiratory tuberculosis have not been associated with asbestos exposure, it appears that the reported "dose response" relation are in fact a measure of other factors unrelated to accumulated asbestos dose.

\section{Discussion}

In evaluating the risks of gastrointestinal cancer to workers exposed to asbestos several problems were encountered.

(1) The studies reviewed made no attempt to evaluate gastrointestinal tract death rates in terms of any of the known risk factors.

(2) Some studies identified the site of the gastrointestinal cancer by an ICD code, others did not. The different ways in which the ICD codes were combined precluded comparisons of cancer risks among the 32 cohorts.

Table 4 Comparison of SMRs for gastrointestinal cancers from studies that included a group of workers not exposed to asbestos

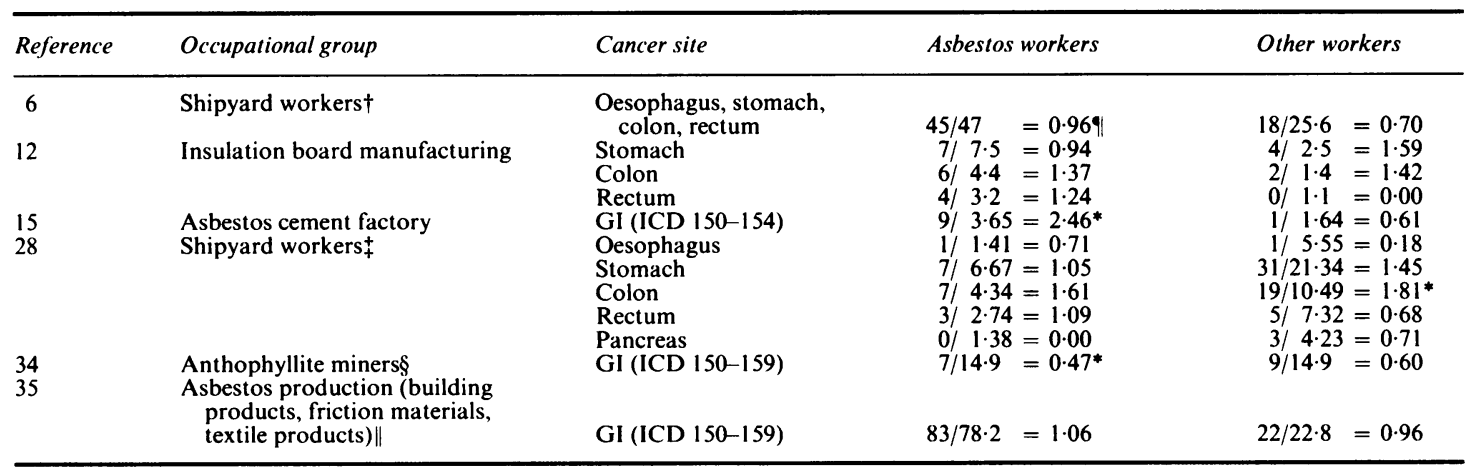

$\mathrm{GI}=$ Gastrointestinal.

${ }^{*} \mathrm{p}<0.05$.

$\dagger$ Non-exposed workers included workers who had no or at most minimal likelihood of asbestos exposure.

+ Separation into asbestos exposed and non-exposed was made on the basis of descriptions of occupations and whether they brought the workers into contact with asbestos.

$\S$ Non-exposed group consisted of subjects selected from an agricultural area with no mines or other industrial plants. This group was matched to the asbestos workers by age and sex, and for date of death for those workers who had died.

Non-exposed group consisted of workers from cotton textile plants.

9 For the exposed group the SMRs were similar for different latency intervals $(0-19,20-29$, $\geqslant 30$ years from first employment $)$ and durations of exposure $(<15, \geqslant 15$ years $)$. For the non-exposed group the SMRs were similar for different latency intervals. 


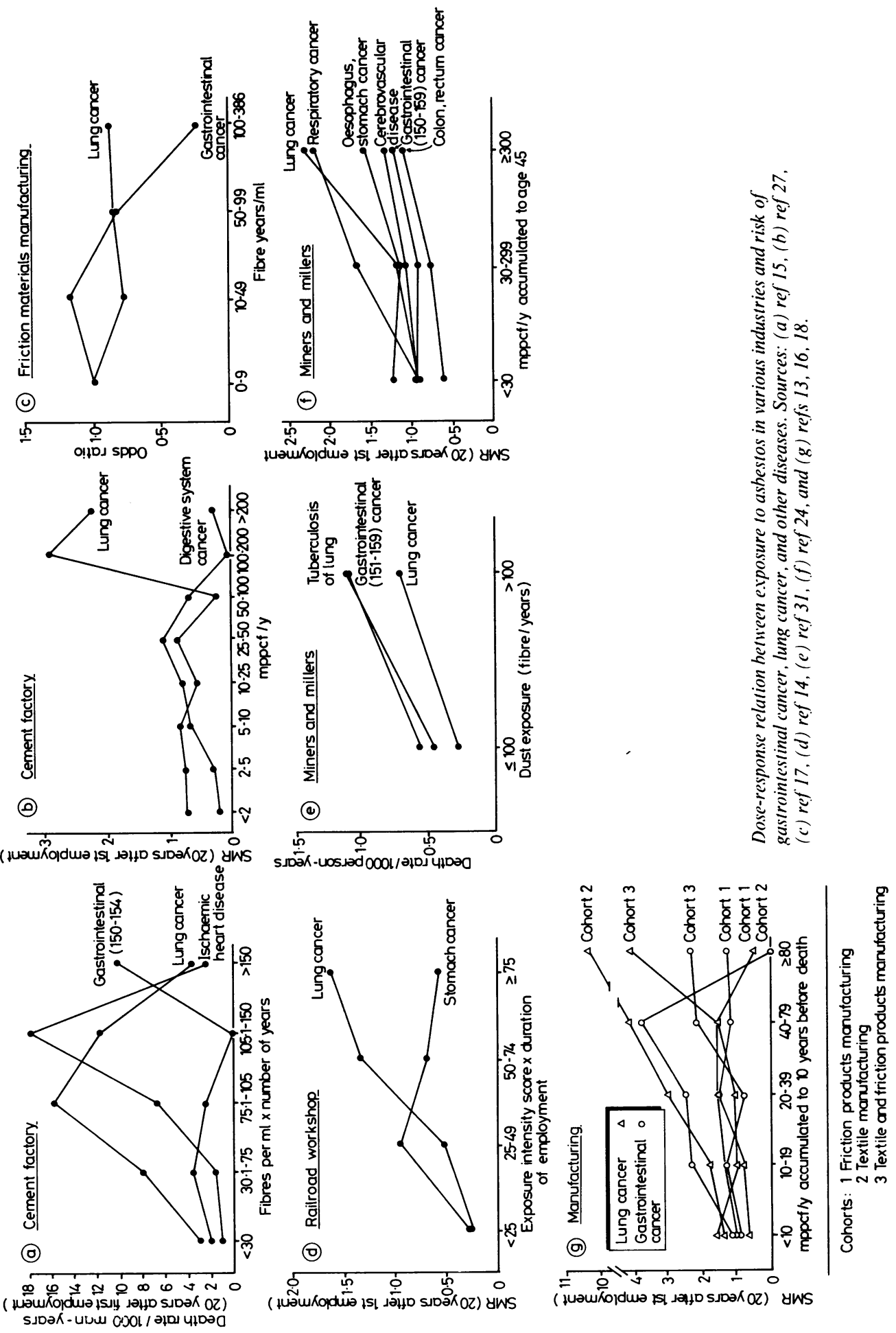


(3) Although mesotheliomas were identified in most studies, in some it was not clear whether these cancers were included or excluded from the group of gastrointestinal cancers, including the group of cancers under GI and ICD codes 150-159.

(4) Since there is a high likelihood of misdiagnosing mesotheliomas as gastrointestinal cancers and since some studies may have included mesotheliomas among the gastrointestinal cancers, the reported SMRs may overestimate the true SMRs for gastrointestinal cancers.

Numerous articles have identified factors that might place an individual at an increased risk of cancer to any gastrointestinal site (ICD codes 150-159). These risk factors include smoking; diet including alcohol, beer, and beef; familial/inheritance factors-for example, adenomatosis; history of ulcerative colitis; and place of residence.

Small but significantly increased relative risks (relative risks less than 2 , for example) may occur because of spurious associations or failure to account for the effects of other risk factors, such as diet or smoking, that might affect the relative risk. For relative risks that lie between 1 and 2 it is extremely difficult to disentangle the various contributions of biased information, confounding of two or more factors, and cause and effect. Doll and Peto note that the simplest and most likely explanation of the excess mortality of gastrointestinal cancer reported for asbestos workers in some studies is from the misdiagnosis of cancer of the lung and mesothelioma of the pleura or peritoneum. ${ }^{38}$ In studies that seek out moderate risks considerable care must be taken both in the analytical methods used and in the interpretation of the results, since the biases inherent in poorly controlled and designed epidemiological studies may exceed the magnitude of the effects that could be observed.

Doll and Peto noted that unless local death specific rates are used, ratios (SMRs) under 1.5 may be largely or wholly artifactual. ${ }^{38}$ The importance of using local death rates is illustrated by the study of brewery workers reported by Dean et al. ${ }^{39}$ These investigators found a higher SMR for colonic cancer based on all Ireland death rates $(1.65, p<0.05)$ than the SMR based on death rates in Dublin county borough $(1 \cdot 18$, $\mathrm{p}>0 \cdot 10)$.

One major difficulty with the dose response data provided in most studies is that the accumulated asbestos dose (either in terms of the quantity of dust or asbestos fibres) is computed for workers in terms of their average exposure in different jobs multiplied by the duration of exposure. This procedure does not differentiate between workers with high exposures of short duration or low exposures of long duration. In addition, if there are no major differences in level of exposure between workers in different job categories the procedure will result in people with longer durations of exposure being placed in the higher exposure groups. These higher exposure groups will tend to include the older workers who are at an increased risk of death, regardless of their exposure to asbestos. One approach to the evaluation of dose response relations that would not suffer from the above deficiency would be to compute mortality risks (SMRs, mortality rates, odds ratios) for cohorts of workers who experienced relatively constant doses of asbestos over time.

The data in the figure show no consistent dose response relation between accumulated asbestos dose and lung cancer. This certainly raised questions concerning the validity of this reported dose response relation. One problem with the lung cancer dose response data is that the lifetime smoking habits of the asbestos workers were not taken into consideration. Even if the smoking habits of the asbestos workers were known similar information was not available on the comparison populations. Since rates of lung cancer generally increase with the duration of smoking, one may expect to find higher SMRs for higher accumulated asbestos doses, especially if the accumulated asbestos dose is computed as a product of the average concentration of asbestos and duration of employment. Since in most of the studies the accumulated asbestos dose was a function of the duration of employment, the dose response relation between lung cancer and accumulated asbestos dose might more correctly reflect a dose response relation between lung cancer and duration of smoking.

If asbestos has a carcinogenic effect on the gastrointestinal tract it should be possible to show this effect through lifetime ingestion studies in laboratory animals. Selikoff and Lee noted that "attempts to induce carcinoma in the intestinal epithelium or mesothelioma in the peritoneum by feeding asbestos have been uniformly disappointing . . ." ${ }^{40}$ In a later review of published studies of asbestos administered by mouth Condie concluded, "the bulk of the experimental evidence indicates that the long-term, high-level ingestion exposure to various types of asbestos fibres failed to produce any definite, reproducible, organ-specific carcinogenic effect." ${ }^{21}$ Condie cited the evidence from 12 studies that had evaluated the carcinogenic effects of ingesting asbestos. In two subsequent life time studies of asbestos ingestion by F344 rats and Syrian golden hamsters McConnell et al reported no increase in the incidence of gastrointestinal cancers ${ }^{4243}$ and reaffirmed the conclusions of Condie. ${ }^{41}$ Ward et al evaluated the effects of intragastically administered asbestos in F344 rats. ${ }^{44}$ Some groups of rats also received subcutaneous injections of azoxymethane (AOM), a known gastrointestinal carcinogen. The proportions of rats that developed intestinal tumours were $66 \cdot 7 \%, 77 \cdot 1 \%$, and 
$32.6 \%$ in the AOM (48 rats), AOM plus amosite asbestos (48 rats), and amosite asbestos (49 rats) treated groups, respectively. The authors noted that F344 rats at the same laboratory "rarely develop intestinal tumours." Several investigators have suggested that the feed of the rats who received amosite might have been contaminated by AOM, thus giving an erroneously high rate of intestinal tumours. ${ }^{41-43}$

The criteria that should be met to establish cause and effect relation have been stated in many different ways by numerous investigators. These criteria as restated by Selikoff and Lee ${ }^{40}$ are that:

(1) a statistically significant association be established between exposures of subjects to the agent (asbestos) and the subsequent development of the syndrome;

(2) some degree of dose response relation should be demonstrable;

(3) in the event that the agent or its metabolic product can be shown in tissue, the concentration in exposed subjects should be greater than in unexposed subjects;

(4) the demonstration of pathological changes in animals after exposure to the agent, similar to those seen in man, would strengthen the evidence for causation, but the failure to obtain such changes would not negate other evidence supporting a causative relation; and

(5) the role of numerous attendant circumstances capable of influencing the appearance of manifestations of the disease initiated by the agent should be evaluated.

The present evaluation found no consistent statistical association between exposure to asbestos and gastrointestinal cancer, a dose response relation was not apparent, and results of ingestion studies in laboratory animals were negative. In terms of these criteria the findings of the present evaluation do not support a cause and effect relation between exposure to asbestos and gastrointestinal cancer. The third criterion was not evaluated since studies have not been conducted to evaluate the concentration of asbestos fibres or bodies in the gastrointestinal tissues of asbestos exposed and non-exposed subjects. Although various factors associated with an increased risk of gastrointestinal cancer have been identified, none of the 32 studies made any adjustments to the risk estimates for gastrointestinal cancer for any of these factors. Based on the epidemiological, clinical, and experimental studies evaluated, there is no evidence to support a cause and effect relation between exposure to asbestos and cancer of any gastrointestinal site.

Requests for reprints to: Dr D A Edelman, Medical Research Consultants, Inc, 6 Winding Creek Lane, Chapel Hill, NC 27514.

\section{References}

1 Selikoff IJ, Churg J, Hammond EC. Asbestos exposure and neoplasia. JAMA 1964;188:142-6.

2 Miller AB. Asbestos fibre dust and gastrointestinal malignancies. Review of literature with regard to a cause/effect relationship. $J$ Chronic Dis 1978;31:23-33.

3 Morgan RW, Foliart DE, Wong $\mathrm{O}$. Asbestos and gastrointestinal cancer. A review of the literature. West J Med 1985;143:60-5.

4 Hodgson JT, Jones RD. Mortality of asbestos workers in England and Wales 1971-81. Br J Ind Med 1986;43:158-64.

5 Woitowitz HJ, Lange HJ, Beierl L, et al. Mortality rates in the Federal Republic of Germany following previous occupational exposure to asbestos dust. Int Arch Occup Environ Health 1986;57:161-71

6 Kolonel LN, Yoshizawa CN, Hirohata T, Myers BC. Cancer occurrence in shipyard workers exposed to asbestos in Hawaii. Cancer Res 1985;45:3924-8.

7 Ohlson C-G, Hogstedt C. Lung cancer among asbestos cement workers. A Swedish cohort study and a review. Br J Ind Med 1985;42:397-402.

8 Hilt B, Langard S, Andersen A, Rosenberg J. Asbestos exposure, smoking habits, and cancer incidence among production and maintenance workers in an electrochemical plant. Am J Ind Med 1985;8:565-77.

9 Peto J, Doll R, Hermon C, Binns W, Clayton R, Goffe T. Relationship of mortality to measures of environmental asbestos pollution in an asbestos textile factory. Ann Occup Med 1985;29:305-55.

10 Cookson WOC, Musk AW, Glancy JJ, et al. Compensation, radiographic changes, and survival in applicants for asbestosis compensation. Br J Ind Med 1985;42:461-8.

11 Newhouse ML. Berry G. Wagner JC. Mortality of factory workers in east London 1933-80. Br J Ind Med 1985;42:4-11.

12 Acheson ED, Gardner MJ, Winter PD, Bennett C. Cancer in a factory using amosite asbestos. Int $J$ Epidemiol 1984:13:3-10.

13 McDonald AD. Fry JS, Woolley AJ, McDonald JC. Dust exposure and mortality in an American chrysotile asbestos friction products plant. Br $J$ Ind Med 1984:41:151-7.

14 Ohlson C-G, Klaesson B, Hogstedt C. Mortality among asbestosexposed workers in a railroad workshop. Scand $J$ Work Environ Health 1984:10:283-91.

15 Finkelstein MM. Mortality among employees of an Ontario asbestos-cement factory. Am Rev Respir Dis 1984;129:754-61.

16 McDonald AD, Fry JS, Woolley AJ, McDonald J. Dust exposure and mortality in an American chrysotile textile plant. $\mathrm{Br} J$ Ind Med 1983;40:361-7.

17 Berry G, Newhouse ML. Mortality of workers manufacturing friction materials using asbestos. Br J Ind Med 1983:40:1-7.

18 McDonald AD, Fry JS. Woolley AJ, McDonald JC. Dust exposure and mortality in an American factory using chrysotile, amosite, and crocidolite in mainly textile manufacturing. $\mathrm{Br} J$ Ind Med 1982:39:368-74.

19 Thomas HF. Benjamin IT, Elwood PC. Sweetnam PM. Further follow-up study of workers from an asbestos cement factory. $\mathrm{Br}$ J Ind Med 1982;39:273-6.

20 Acheson ED. Gardner MJ. Pippard EC. Grime LP. Mortality of two groups of women who manufactured gas masks from chrysotile and crocidolite asbestos: a 40-year follow-up. Br J Ind Med 1982;39:344-8.

21 Berry G. Mortality of workers certified by pneumoconiosis medical panels as having asbestosis. $\mathrm{Br} J$ Ind Med 1981:38: 130-7.

22 Finkelstein M, Kusiak R. Suranyi G. Mortality among workers receiving compensation for asbestosis in Ontario. Can Med Assoc $J$ 1981:125:259-62.

23 Jones JSP. Pooley FD. Sawle GW, et al. The consequences of exposure to asbestos dust in a wartime gas-mask factory. In Wagner JC. ed. Biological effects of mineral fihres. Geneva: International Agency for Research on Cancer. 1980:637-53. 
(Sci publ No 30.)

24 McDonald JC, Liddell FDK, Gibbs GW, Eyssen GE, McDonald AD. Dust exposure and mortality in chrysotile mining, 1919-75. Br J Ind Med 1980;37:11-24.

25 Selikoff IJ, Seidman H, Hammond EC. Mortality effects of cigarette smoking among amosite asbestos factory workers. $J$ Natl Cancer Inst 1980;65:507-13.

26 Rossiter CE, Coles RM. HM Dockyard, Devonport: 1947 mortality study. In: Wagner JC, ed. Biological effects of mineral fibres. Geneva: International Agency for Research on Cancer, 1980:713-21. (Sci publ No 30.)

27 Hughes J, Weill $\mathrm{H}$. Lung cancer risk associated with manufacture of asbestos cement products. In: Wagner JC, ed. Biological effects of mineral fibres. Geneva: International Agency for Research on Cancer, 1980:627-35. (Sci publ No 30.)

28 Puntoni R, Vercelli M, Merlo F, Valeiro F, Santi L. Mortality among shipyard workers in Genoa, Italy. Ann NY Acad Sci 1979;330:353-77.

29 Henderson V, Enterline PE. Asbestos exposure: factors associated with excess cancer and respiratory disease mortality. Ann NY Acad Sci 1979;330:117-26.

30 Hammond EC, Selikoff IJ, Seidman H. Asbestos exposure, cigarette smoking and death rates. Ann NY Acad Sci 1979;330:473-90.

31 Rubino GF, Piolatto G, Newhouse ML, Scansetti G, Aresini GA, Murray R. Mortality of chrysotile asbestos workers at the Balangero Mine, Northern Italy. Br J Ind Med 1979;36:187-94.

32 Nicholson WJ, Selikoff IJ, Seidman H, Lilis R, Formby P. Longterm mortality experience of chrysotile miners and millers in Thetford Mines, Quebec. Ann NY Acad Sci 1979;330:11-21.
33 Weiss W. Mortality of a cohort exposed to chrysotile asbestos. J Occup Med 1977;19:737-40.

34 Meurman LO, Kiviluoto R, Hakama M. Mortality and morbidity among the working population of anthophyllite asbestos miners in Finland. Br J Ind Med 1974;31:105-12.

35 Enterline PE, Kendrick MA. Asbestos-dust exposures at various levels and mortality. Arch Environ Health 1967;15:181-6.

36 Bailar JC, Ederer F. Significance factors for the ratio of a Poisson variable to its expectation. Biometrics 1964;20:639-43.

37 Browne $\mathrm{K}$. A threshold for asbestos related lung cancer. $\mathrm{Br} \mathrm{J}$ Ind Med 1986;43:556-8.

38 Doll R, Peto J. Asbestos. Effects on health of exposure to asbestos. London: HMSO, 1985

39 Dean G, MacLennan R, McLoughlin H, Shelley E. Cause of death of blue-collar workers at a Dublin Brewery, 1954-73. Br J Cancer 1979;40:581-9.

40 Selikoff IJ, Lee DHK. Asbestos and disease. New York: Academic Press, 1979.

41 Condie LW. Review of published studies of orally administered asbestos. Environ Health Perspect 1983;53:3-9.

42 McConnell EE, Shefner AM, Rust JH, Moore JA. Chronic effects of dietary exposure to amosite and chrysotile asbestos in Syrian golden hamsters. Environ Health Perspect 1983;53:11-25.

43 McConnell EE, Rutter HA, Ulland BM, Moore JA. Chronic effects of dietary exposure to amosite asbestos and tremolite in F344 rats. Environ Health Perspect 1983;53:27-44.

44 Ward JM, Frank AL, Wenk M, Devor D, Tarone RE. Ingested asbestos and intestinal carcinogenesis in F344 rats. $J$ Environ Pathol Toxicol 1980;3:301-12.

\section{Correspondence and editorials}

The British Journal of Industrial Medicine welcomes correspondence relating to any of the material appearing in the journal. Results from preliminary or small scale studies may also be published in the correspondence column if this seems appropriate. Letters should be not more than 500 words in length and contain a minimum of references. Tables and figures should be kept to an absolute minimum. Letters are accepted on the understanding that they may be subject to editorial revision and shortening.

The journal now also publishes editorials which are normally specially commissioned. The Editor welcomes suggestions regarding suitable topics; those wishing to submit an editorial, however, should do so only after discussion with the Editor. 